\title{
The Role of Exercise Doppler Echocardiography to Unmask Pulmonary Arterial Hypertension in Selected Patients with Systemic Sclerosis and Equivocal Baseline Echocardiographic Values for Pulmonary Hypertension
}

\author{
Loukianos S. Rallidis 1,*D, Konstantina Papangelopoulou ${ }^{1}$, Anastasia Anthi ${ }^{2}$, Iraklis Tsangaris ${ }^{2} \mathbb{D}$, \\ Christos Varounis ${ }^{1}$, Georgios Makavos ${ }^{1}$, Dimitrios Konstantonis ${ }^{2}$, Panagiotis Vlachoyiannopoulos ${ }^{3}$, \\ Stylianos E. Orfanos ${ }^{2}$ and Efstathios K. Iliodromitis ${ }^{1}$
}

1 Second Department of Cardiology and Pulmonary Hypertension Clinic, School of Medicine, National \& Kapodistrian University of Athens, Attikon Hospital, 16462 Athens, Greece; kpapanel@gmail.com (K.P.); varounis@hotmail.com (C.V.); gmakavos@hotmail.com (G.M.); iliodromitis@yahoo.gr (E.K.I.)

2 Second Department of Critical Care and Pulmonary Hypertension Clinic, School of Medicine, National \& Kapodistrian University of Athens, Attikon Hospital, 16462 Athens, Greece;

check for

updates

Citation: Rallidis, L.S.;

Papangelopoulou, K.; Anthi, A.;

Tsangaris, I.; Varounis, C.; Makavos,

G.; Konstantonis, D.;

Vlachoyiannopoulos, P.; Orfanos, S.E.; Iliodromitis, E.K. The Role of Exercise

Doppler Echocardiography to

Unmask Pulmonary Arterial

Hypertension in Selected Patients with Systemic Sclerosis and Equivocal Baseline Echocardiographic Values for Pulmonary Hypertension.

Diagnostics 2021, 11, 1200. https://

doi.org/10.3390/diagnostics11071200

Academic Editor: Andrea D. Annoni

Received: 6 June 2021

Accepted: 29 June 2021

Published: 2 July 2021

Publisher's Note: MDPI stays neutral with regard to jurisdictional claims in published maps and institutional affiliations.

Copyright: (c) 2021 by the authors. Licensee MDPI, Basel, Switzerland. This article is an open access article distributed under the terms and conditions of the Creative Commons Attribution (CC BY) license (https:/ / creativecommons.org/licenses/by/ $4.0 /)$. anastasia.anthi1@gmail.com (A.A.); itsagkaris@med.uoa.gr (I.T.); dkonstantonis@gmail.com (D.K.); stylianosorfanosuoa@gmail.com (S.E.O.)

3 Department of Pathophysiology, School of Medicine, National \& Kapodistrian University of Athens, 11527 Athens, Greece; pvlah@med.uoa.gr

* Correspondence: lrallidis@gmail.com; Tel.: +30-210-992-9106

Abstract: Recently, a lower mean pulmonary arterial pressure (PAP) cutoff of $>20 \mathrm{mmHg}$ for pulmonary hypertension $(\mathrm{PH})$ definition has been proposed. We examined whether exercise Doppler echocardiography (EDE) can unmask PA hypertension (PAH) in systemic sclerosis (SSc) patients whose baseline echocardiography for $\mathrm{PH}$ is equivocal. We enrolled 49 patients with SSc who underwent treadmill EDE. Tricuspid regurgitation (TR) velocity was recorded immediately after EDE. Inotropic reserve of right ventricle (RV) was assessed by the change (post-prior to exercise) of tissue Doppler imaging-derived peak systolic velocity (S) of tricuspid annulus. Inclusion criteria comprised preserved left and RV function, and baseline TR velocity between 2.7 and $3.2 \mathrm{~m} / \mathrm{s}$. All patients had right-heart catheterization (RHC) within $48 \mathrm{~h}$ after EDE. From 46 patients with good quality of post-exercise TR velocity, RHC confirmed PAH in 21 (45.6\%). Post-exercise TR velocity $>3.4 \mathrm{~m} / \mathrm{s}$ had a sensitivity of $90.5 \%$, a specificity of $80 \%$ and an accuracy of $84.8 \%$ in detecting PAH. Inotropic reserve of RV was positively correlated with maximum achieved workload in METs $(r=0.571, p<0.001)$. EDE has a good diagnostic accuracy for the identification of PAH in selected SSc patients whose baseline echocardiographic measurements for PH lie in the gray zone, and it is also potentially useful in assessing RV contractile reserve.

Keywords: exercise Doppler echocardiography; pulmonary arterial hypertension; systemic sclerosis

\section{Introduction}

Systemic sclerosis (SSc) is an autoimmune rheumatic disease commonly complicated by pulmonary hypertension (PH) [1]. In most cases, $\mathrm{PH}$ in SSc is due to pulmonary arterial hypertension (PAH) [2]. The prevalence of PAH in SSc ranges from 5\% to 12\% [3] and it is the leading cause of death in these patients $[4,5]$.

Early diagnosis of $\mathrm{PH}$ in SSc is of critical importance, not only because of the rapid progression of the disease but also because it can lead to timely initiation of treatment [6] and improvement of survival, particularly in patients under the age of 70 years [7]. It has been indicated by randomized controlled studies that treatment of mildly symptomatic patients with PAH is effective in terms of improvement in exercise capacity, functional class, 
hemodynamics, echocardiographic parameters associated with $\mathrm{PH}$ and delay of clinical worsening [8]. While the "gold standard" for PH diagnosis remains the measurement of pulmonary arterial pressure (PAP) by right-heart catheterization (RHC) [3], resting echocardiography is the most useful tool for $\mathrm{PH}$ screening, as it provides a noninvasive assessment of systolic PAP (sPAP) using tricuspid regurgitation (TR) velocity, which correlates well with invasive measurements [9]. However, resting echocardiography is of limited accuracy for the detection of elevated PAP in SSc, particularly if TR velocity is $<3.4 \mathrm{~m} / \mathrm{s}$ [10]. SSc patients often complain of dyspnea on exertion without echocardiographic evidence of $\mathrm{PH}$ at rest [11].

Exercise Doppler echocardiography (EDE) in SSc patients has been proposed as a useful technique for detection of elevations in SPAP during exercise, suggestive of subclinical PAH due to progressive remodeling and functional abnormalities of the pulmonary arterial vasculature $[11,12]$. However, the role of EDE in the detection of exercise-induced PH has been downgraded in the 2015 ESC/ERS guidelines for the diagnosis and treatment of $\mathrm{PH}$ because of limited standardization and a lack of prospective confirmatory data $[3,13]$. However, exercise echocardiography can provide additional information beyond changes in sPAP by assessing the exercise tolerance, the right ventricular (RV) contractile reserve and the left ventricular (LV) diastolic function [14].

Recently, the cutoff value for the definition of $\mathrm{PH}$ was set at the level of mean PAP $>20 \mathrm{mmHg}$, measured by RHC [15]. This challenged us to evaluate the potential usefulness of EDE to unmask the presence of PAH in selected asymptomatic or mildly symptomatic patients with SSc, whose resting echocardiographic sPAP fall within the "gray zone" $(\mathrm{sPAP}=35-45 \mathrm{mmHg}$, which corresponds to TR velocity $=2.7-3.2 \mathrm{~m} / \mathrm{s}$ ).

\section{Methods}

\subsection{Study Population}

We prospectively recruited consecutive patients with established SSc who were referred to the PH clinic of our center for screening for PAH. Patients seen in the PH clinic routinely undergo a detailed clinical work-up which includes resting echocardiogram, 6-minute walk test (6-MWT), pulmonary function tests and laboratory tests, including $\mathrm{N}$-terminal pro-brain natriuretic peptide (NT-proBNP).

Inclusion criteria for our study comprised: (1) preserved left ventricular (LV) function (ejection fraction $(\mathrm{EF})>55 \%$ ) and right ventricular (RV) function (tricuspid annulus plane systolic excursion (TAPSE) $\geq 16 \mathrm{~mm}$ ), (2) no history of previous ischemic or valvular heart disease or echocardiographic evidence of diastolic dysfunction consistent with elevated LV filling pressure, (3) presence of TR with a good-quality signal on Doppler, (4) sinus rhythm, (5) baseline maximal TR velocity in the range of $2.7-3.2 \mathrm{~m} / \mathrm{s}$ and (6) forced expiratory volume in $1 \mathrm{~s}\left(\mathrm{FEV}_{1}\right) \geq 55 \%$ of predicted normal and total lung capacity (TLC) $\geq 60 \%$ of predicted normal [16].

The study was approved by the ethics committee of our institution and all subjects provided signed informed consent. The study was conducted according to the guidelines of the Declaration of Helsinki, and approved by the Ethics Committee of University General Hospital Attikon. Approval number: EB $\Delta 36$. Date of approval 14 February 2014.

\subsection{Resting Echocardiography}

A comprehensive resting echocardiography study was performed during the visit to the PH clinic with a Vivid 9 ultrasound system (GE Medical Systems, Horten, Norway). All echocardiographic studies were performed by a single operator (L.S.R.) and the measurements were performed according to the current guidelines of the American Society of Echocardiography and the European Association of Cardiovascular Imaging [17]. Assessment of diastolic function was based on pulsed-wave Doppler of transmitral flow $E$ and A waves and deceleration time. Tissue Doppler imaging (TDI) pulsed-wave velocities in early diastole ( $\mathrm{e}^{\prime}$ wave) were recorded at the lateral mitral annulus aspect and septal basal regions from the apical four-chamber view [18]. The average E/e' ratio was calculated by 
taking the mean of lateral and septal $\mathrm{e}^{\prime}$ waves. Markers of RV function, such as TAPSE, and TDI-derived peak systolic velocity $(S)$ of the tricuspid annulus (S(RV)) were also recorded. TR velocity was measured with continuous-wave Doppler. Right atrial pressure (RAP) was calculated from the inferior vena cava (IVC) diameter and its respiratory variation [19]. sPAP was calculated according to the Bernoulli equation: $\mathrm{SPAP}=4 \times(\text { TR velocity })^{2}+\mathrm{RAP}$.

A repeat resting echocardiographic study was performed the day of RHC. For comparisons of echocardiographic with RHC measurements, the echocardiographic values obtained the day of RHC were used.

\subsection{Exercise Doppler Echocardiography}

EDE was performed using a modified Bruce protocol. The modified protocol was preferred over the standard because patients unfamiliar with treadmill (usually elderly women) were more compliant to perform this "softer" protocol. Exercise was terminated when patients achieved $85 \%$ of the predicted maximal heart rate or until their exercise capacity was limited by symptoms, i.e., symptoms-limited exercise test. Echocardiographic images were acquired prior to (special attention was paid to accurate measurement of maximal TR velocity) and immediately after conclusion of the treadmill exercise. In particular, upon completion of the study, the patients returned to the bed which was situated beside the treadmill machine at lateral decubitus position, and TR velocity was first measured followed by evaluation of RV systolic function and LV diastolic function from the four-chamber view. All measurements were obtained within $1 \mathrm{~min}$ by a single operator (L.S.R.) with expertise in EDE [20]. RV systolic exercise reserve was defined by the difference (denoted by " $\Delta$ ") between post-exercise and respective baseline values of TAPSE and $S(R V)$. Additional measurements included resting heart rate and blood pressure (BP), as well peak heart rate and $\mathrm{BP}$, total time of exercise and maximum workload estimated by standard metabolic equivalents (METs).

\subsection{Right-Heart Catheterization}

All participants underwent RHC in a supine position using an echo-guided right internal jugular vein access. The following measurements were performed: RAP, PAP (systolic, diastolic and mean), pulmonary arterial wedge pressure (PAWP) and cardiac output (CO) by thermodilution. Pulmonary vascular resistance (PVR) was subsequently calculated.

\subsection{6-Minute Walk Test}

Patients performed a 6-MWT under the guidance and supervision of an expert nurse. A pre-marked corridor was used, and total walking distance was measured as well as percutaneous oxygen saturation at the end of the test.

\subsection{Pulmonary Function Tests and Lung Imaging}

All patients underwent chest-XR, high-resolution computed tomography (CT) of lungs and pulmonary function tests including $\mathrm{FEV}_{1}$ and TLC.

\subsection{Biochemical Measurements}

Blood was taken from all patients for NT-proBNP and high-sensitivity C-reactive protein (hsCRP) measurements, as well as for routine hematological and biochemical tests.

\subsection{Statistical Analysis}

Continuous variables are presented as means \pm standard deviation (SD), while nonnormally distributed variables are presented as medians and interquartile ranges. The Student's $t$ test was applied for independent samples to compare means for normally distributed variables or the Mann-Whitney test for skewed variables.

Cutoff analysis using receiver operating characteristic (ROC) analysis revealed the optimal cutoff value with the best combination of sensitivity and specificity that discriminates patients according to whether they had PAH or not. Sensitivity, specificity, disease 
prevalence, positive and negative predictive value as well as accuracy are expressed as percentages. Confidence intervals (CIs) for sensitivity, specificity and accuracy are "exact" Clopper-Pearson CIs. CIs for the likelihood ratios are calculated using the "Log method" [21]. CIs for the predictive values are the standard logit CIs [22].

A $p$-value $<0.05$ was considered significant. The SPSS version 26 (SPSS Inc., Chicago, IL, USA) statistical package was used.

\section{Results}

During the period 2016-2020, 52 out of 190 consecutive patients with SSc referred to the PH clinic fulfilled the inclusion criteria. Of those, 3 had a poor-quality TR Doppler signal in post-exercise echocardiography and 3 were unable to perform the treadmill exercise due to severe musculoskeletal problems. Thus, the final study group comprised 46 patients with SSc. Of those, $37(80 \%)$ had diffused cutaneous SSc and $9(20 \%)$ had limited cutaneous SSc (CREST syndrome). The majority of patients (44 of 46) were women. The mean disease duration from first symptoms related to SSc at the time of the first visit was $7.4 \pm 5.1$ years (Table 1$)$.

Table 1. Characteristics of patients with systemic sclerosis according to the presence of pulmonary arterial hypertension (PAH).

\begin{tabular}{|c|c|c|c|c|}
\hline Characteristics & All Patients & $\begin{array}{l}\text { Patients with PAH } \\
\quad(n=21)\end{array}$ & $\begin{array}{l}\text { Patients without PAH } \\
\quad(n=25)\end{array}$ & $p$-Value * \\
\hline Age (years) & $61.4 \pm 10.7$ & $57.8 \pm 9.5$ & $62.9 \pm 10.6$ & 0.087 \\
\hline Body mass index $\left(\mathrm{kg} / \mathrm{m}^{2}\right)$ & $25.7 \pm 4.3$ & $25.5 \pm 5.8$ & $25.8 \pm 2.7$ & 0.805 \\
\hline Duration of disease (years) & $7.4 \pm 5.1$ & $5.9 \pm 4.1$ & $8.0 \pm 5.4$ & 0.257 \\
\hline $\mathrm{FEV}_{1}, \%$ predicted & $75.6 \pm 17.8$ & $73.5 \pm 16.4$ & $78.4 \pm 19.9$ & 0.529 \\
\hline TLC, \% predicted & $75.6 \pm 7.1$ & $76.3 \pm 7.1$ & $74.5 \pm 7.1$ & 0.480 \\
\hline 6-minute walk test $(\mathrm{m})$ & $452.2 \pm 72.9$ & $456.8 \pm 72.9$ & $459.2 \pm 66.7$ & 0.917 \\
\hline \multicolumn{5}{|l|}{ Baseline echocardiography (echo) } \\
\hline Ejection fraction of left ventricle (\%) & $63.8 \pm 3.4$ & $63.1 \pm 3.7$ & $64.3 \pm 3.1$ & 0.228 \\
\hline $\mathrm{E} / \mathrm{e}^{\prime}$ (average) & $10.1 \pm 2.3$ & $9.3 \pm 1.7$ & $10.6 \pm 2.6$ & 0.068 \\
\hline Left atrial index $\left(\mathrm{mL} / \mathrm{m}^{2} \mathrm{BSA}\right)$ & $27.3 \pm 3.9$ & $26.8 \pm 4.5$ & $27.6 \pm 3.7$ & 0.523 \\
\hline TAPSE $(\mathrm{mm})$ & $22.4 \pm 4.3$ & $21.3 \pm 3.3$ & $24.0 \pm 3.4$ & 0.012 \\
\hline $\mathrm{S}(\mathrm{RV})(\mathrm{cm} / \mathrm{s})$ & $13.5 \pm 2.9$ & $12.3 \pm 2.9$ & $14.8 \pm 2.2$ & $<0.001$ \\
\hline Right atrial pressure (mmHg) & $3.8 \pm 1.8$ & $4.5 \pm 2.1$ & $3.2 \pm 1.0$ & 0.011 \\
\hline TR velocity $(\mathrm{m} / \mathrm{s})$ & $2.85 \pm 0.19$ & $2.92 \pm 0.16$ & $2.74 \pm 0.08$ & $<0.001$ \\
\hline sPAP (mmHg) & $35.4 \pm 4.1$ & $38.2 \pm 4.2$ & $32.9 \pm 2.1$ & $<0.001$ \\
\hline \multicolumn{5}{|l|}{ Right-heart catheterization } \\
\hline Right atrial pressure (mmHg) & $4.2 \pm 2.0$ & $4.8 \pm 2.3$ & $3.8 \pm 1.9$ & 0.157 \\
\hline PAWP $(\mathrm{mmHg})$ & $7.3 \pm 2.3$ & $7.1 \pm 2.1$ & $7.5 \pm 2.6$ & 0.552 \\
\hline Mean PAP (mmHg) & $19.5 \pm 5.6$ & $25.6 \pm 2.9$ & $15.9 \pm 3.0$ & $<0.001$ \\
\hline $\mathrm{sPAP}(\mathrm{mmHg})$ & $30.6 \pm 6.8$ & $37.3 \pm 3.6$ & $25.8 \pm 3.9$ & $<0.001$ \\
\hline Cardiac output $(\mathrm{L} / \mathrm{min})$ & $5.0 \pm 1.3$ & $4.45 \pm 0.92$ & $5.45 \pm 1.21$ & 0.005 \\
\hline PVR (Woods Units) & $2.63 \pm 1.49$ & $4.21 \pm 0.97$ & $1.58 \pm 0.42$ & $<0.001$ \\
\hline \multicolumn{5}{|l|}{ Treadmill exercise } \\
\hline Duration (min) & $6.8 \pm 3.7$ & $5.15 \pm 3.2$ & $8.26 \pm 3.7$ & 0.005 \\
\hline \multicolumn{5}{|l|}{ Peak } \\
\hline Heart rate $(\mathrm{b} / \mathrm{min})$ & $141.4 \pm 18.1$ & $140.1 \pm 13.8$ & $141.7 \pm 21.1$ & 0.770 \\
\hline METs & $6.1 \pm 2.9$ & $4.6 \pm 2.1$ & $7.0 \pm 3.0$ & 0.004 \\
\hline $\mathrm{sBP}(\mathrm{mmHg})$ & $150.0 \pm 25.4$ & $139.7 \pm 21.6$ & $160.3 \pm 22.9$ & 0.006 \\
\hline \multicolumn{5}{|l|}{ Immediate post-exercise echo } \\
\hline $\mathrm{E} / \mathrm{e}^{\prime}$ (average) & $9.1 \pm 2.2$ & $8.6 \pm 2.1$ & $9.5 \pm 2.2$ & 0.175 \\
\hline TR velocity $(\mathrm{m} / \mathrm{s})$ & $3.4 \pm 0.44$ & $3.77 \pm 0.36$ & $3.14 \pm 0.26$ & $<0.001$ \\
\hline sPAP (mmHg) & $51.1 \pm 12.9$ & $61.57 \pm 10.97$ & $42.65 \pm 7.09$ & $<0.001$ \\
\hline TAPSE (mm) & $26.9 \pm 5.1$ & $24.6 \pm 4.4$ & $29.4 \pm 4.0$ & $<0.001$ \\
\hline $\mathrm{S}(\mathrm{RV})(\mathrm{cm} / \mathrm{sec})$ & $18.7 \pm 4.4$ & $16.7 \pm 4.2$ & $21.2 \pm 4.4$ & 0.001 \\
\hline$\Delta$ (TAPSE) (mm) & $4.5 \pm 2.8$ & $3.4 \pm 2.0$ & $5.4 \pm 3.0$ & 0.017 \\
\hline$\Delta(\mathrm{S}(\mathrm{RV}))(\mathrm{cm} / \mathrm{s})$ & $5.5 \pm 3.3$ & $4.3 \pm 3.2$ & $6.3 \pm 3.1$ & 0.043 \\
\hline \multicolumn{5}{|l|}{ Biochemistry } \\
\hline hsCRP (mg/L) & $3.2(3.1-5.1)$ & $3.35(3.1-7.1)$ & $3.11(3.1-4.8)$ & 0.462 \\
\hline NT-proBNP (pg/mL) & $190.1 \pm 169.4$ & $177.9 \pm 166.8$ & $208.4 \pm 169.2$ & 0.556 \\
\hline Creatinine (mg/dL) & $0.80 \pm 0.21$ & $0.75 \pm 0.14$ & $0.83 \pm 0.25$ & 0.227 \\
\hline Hematocrit $(\%)$ & $38.9 \pm 2.4$ & $39.0 \pm 1.8$ & $38.85 \pm 3.1$ & 0.864 \\
\hline
\end{tabular}

* comparison between PAH patients with those without PAH, $\mathrm{FEV}_{1}=$ forced expiratory volume in $1 \mathrm{~s}$, TLC = total lung capacity, BSA = body surface area, $\mathrm{PVR}=$ pulmonary vascular resistance, $\mathrm{sPAP}=$ systolic pulmonary arterial pressure, $\mathrm{PAWP}=$ pulmonary arterial wedge pressure, TAPSE $=$ tricuspid annular plane systolic excursion, TR $=$ tricuspid regurgitation, NT-proBNP $=\mathrm{N}$-terminal-pro brain natriuretic peptide, $\mathrm{METs}=$ metabolic equivalents $(1 \mathrm{MET}=1 \mathrm{kcal} / \mathrm{kg} / \mathrm{h}), \mathrm{RV}=$ right ventricle, hsCRP = high-sensitivity C-reactive protein, $\mathrm{S}=$ systolic velocity of the tricuspid annulus, $\mathrm{sBP}=$ systolic blood pressure. 
RHC confirmed the presence of PAH (mean PAP $>20 \mathrm{mmHg}$, PAWP $<15 \mathrm{mmHg}$ and PVR $>3$ Wood Units) in 21 patients $(45.6 \%)$. With the previous cutoff level of mean PAP $>25 \mathrm{mmHg}$, only 10 patients $(21.7 \%)$ would have been classified in the PAH group. Resting sPAP estimated by echocardiography the day of RHC was positively corelated with sPAP measured by RHC $(r=0.658, p<0.001)$.

Table 1 shows patients' features according to the presence of PAH. Patients with PAH achieved higher post-exercise TR velocity, had lower RV inotropic response (indicated by lower $\Delta(\mathrm{S}(\mathrm{RV}))$ and $\Delta$ (TAPSE)) and poorer exercise capacity (achieved METs) compared with patients without PAH. There was no difference between the two groups in NT-proBNP and hsCRP levels as well in the post-exercise ratio E/e'.

ROC curve analysis of post-exercise TR velocity discriminated the patients according to those with RHC-confirmed PAH and those without (AUC $=0.927$, with $95 \%$ CI: $0.856-0.997$, $p<0.001)$. A cutoff value of post-exercise TR velocity $>3.4 \mathrm{~m} / \mathrm{s}$ had a sensitivity of $90.5 \%$, a specificity of $80 \%$ and an accuracy of $84.8 \%$ in detecting PAH validated by RHC (Table 2). The selected cutoff value had the highest combination of sensitivity and specificity. In addition, ROC curve analysis of the difference "(post-exercise)-(prior to exercise) TR velocity" discriminated the patients according to those with RHC-confirmed PAH and those without (AUC $=0.834$, with $95 \% \mathrm{CI}$ : 0.714-0.955, $p<0.001$ ). A cutoff value of the difference of "(post-exercise)-(prior to exercise) TR velocity" $>0.5 \mathrm{~m} / \mathrm{s}$ had a sensitivity of $90.5 \%$, a specificity of $64 \%$ and an accuracy $76 \%$ in detecting PAH validated by RHC (Table 3).

Table 2. Diagnostic test evaluation of the post-exercise tricuspid regurgitation velocity $>3.4 \mathrm{~m} / \mathrm{s}$.

\begin{tabular}{ccc}
\hline & Point Estimate & $\mathbf{9 5 \% C I}$ \\
\hline Sensitivity (\%) & 90.5 & $69.6-98.8$ \\
Specificity (\%) & 80.0 & $59.3-93.1$ \\
LR+ & 4.52 & $2.0-10.0$ \\
LR- & 0.12 & $0.03-0.45$ \\
PPV (\%) & 79.1 & $63.1-89.3$ \\
NPV (\%) & 90.9 & $72.5-97.4$ \\
Accuracy (\%) & 84.8 & $71.1-93.6$
\end{tabular}

$\overline{\mathrm{CI}}=$ confidence interval, $\mathrm{LR}+=$ positive likelihood ratio, $\mathrm{LR}-=$ negative likelihood ratio, $\mathrm{PPV}=$ positive predictive value, $\mathrm{NPV}=$ negative predictive value.

Table 3. Diagnostic test evaluation of the difference "(post-exercise)-(prior to exercise) tricuspid regurgitation velocity" $>0.5 \mathrm{~m} / \mathrm{s}$.

\begin{tabular}{ccc}
\hline & Point Estimate & $\mathbf{9 5 \% C I}$ \\
\hline Sensitivity (\%) & 90.5 & $69.6-98.8$ \\
Specificity (\%) & 64.0 & $42.5-82.0$ \\
LR+ & 2.51 & $1.46-4.32$ \\
LR- & 0.15 & $0.04-0.57$ \\
PPV (\%) & 67.8 & $55.09-78.3$ \\
NPV (\%) & 88.9 & $67.5-96.8$ \\
Accuracy (\%) & 76.0 & $61.2-87.4$
\end{tabular}

$\overline{\mathrm{CI}}=$ confidence interval, $\mathrm{LR}+=$ positive likelihood ratio, $\mathrm{LR}-=$ negative likelihood ratio, $\mathrm{PPV}=$ positive predictive value, NPV = negative predictive value.

Post-exercise TR velocity was positively correlated with resting sPAP $(r=0.679$, $p<0.001)$ (Figure 1) and mean PAP $(r=0.659, p<0.001)$ (Figure 2) obtained by RHC, while maximal achieved workload in METs was inversely correlated with mean PAP $(r=-0.461, p=0.003)$ (Figure 3$)$ and PVR $(r=-0.428, p=0.005)$. In addition, exercise systolic inotropic reserve of RV assessed by $\Delta(\mathrm{S}(\mathrm{RV}))$ was positively correlated with METs $(r=0.571, p<0.001)$ (Figure 4$)$ and with 6-MWT $(r=0.436, p=0.01)$, while $\Delta$ (TAPSE) did not show similar correlations $(p>0.05)$. 


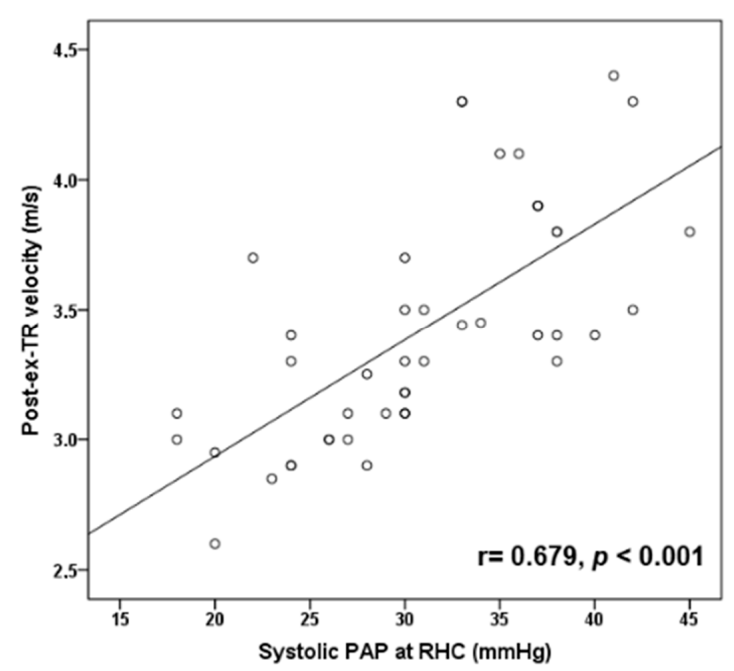

Figure 1. Scatter plot correlation of post-exercise tricuspid regurgitation velocity (post-ex-TR velocity) with resting systolic pulmonary arterial pressure (PAP) at right-heart catheterization (RHC).

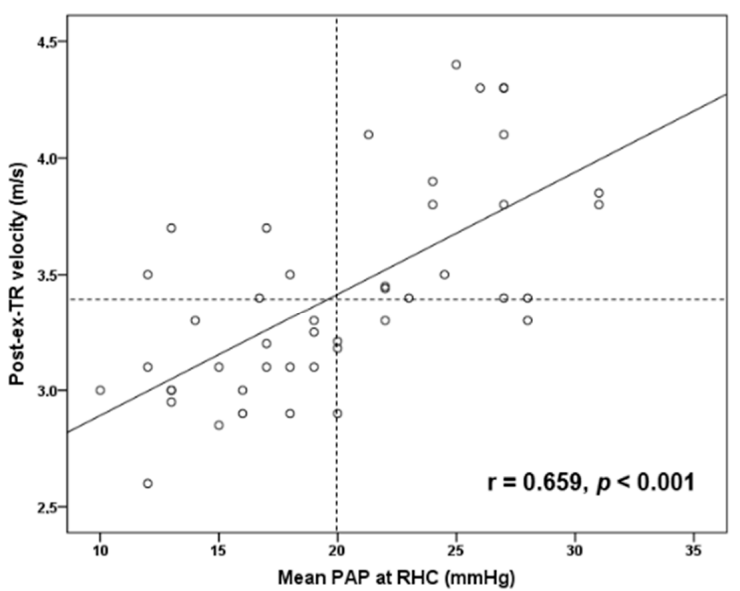

Figure 2. Scatter plot correlation of post-exercise tricuspid regurgitation velocity (post-ex-TR velocity) with resting mean pulmonary arterial pressure (PAP) at right-heart catheterization (RHC). Vertical dashed line indicates mean PAP of $20 \mathrm{mmHg}$, while horizontal dashed line indicates post-ex-TR velocity of $3.4 \mathrm{~m} / \mathrm{s}$.

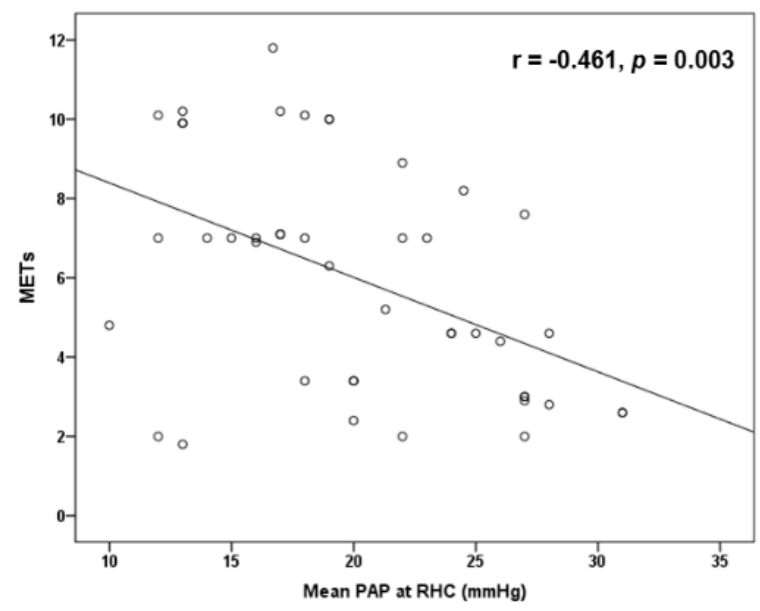

Figure 3. Scatter plot inverse correlation of maximal achieved workload in METs with resting mean pulmonary arterial pressure (PAP) at right-heart catheterization (RHC). 


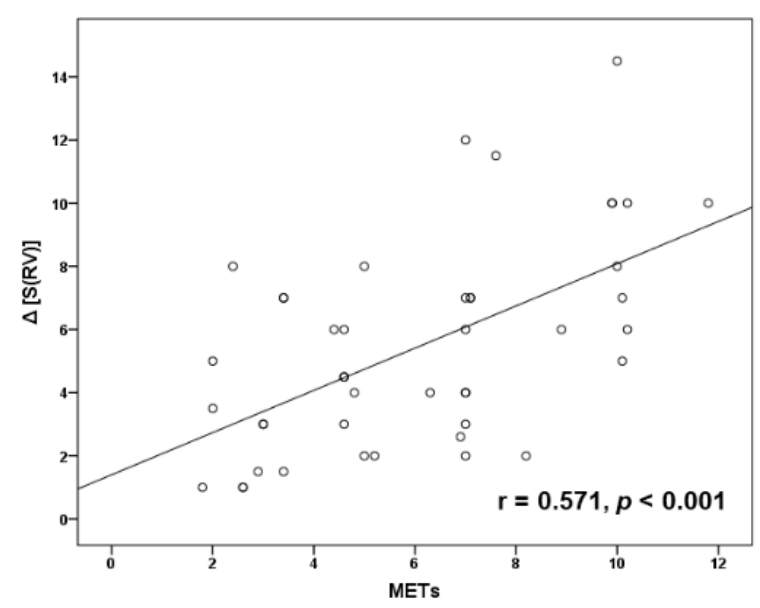

Figure 4. Scatter plot correlation of maximal achieved workload in METs with right ventricular (RV) inotropic reserve defined by the difference between post-exercise and prior to exercise $S$ wave of RV, i.e., $\Delta(\mathrm{S}(\mathrm{RV}))$.

\section{Discussion}

In this study, we showed that EDE is a useful tool for the early detection of PAH in selected asymptomatic or mildly symptomatic patients with SSc whose baseline echocardiographic measurements for $\mathrm{PH}$ fall in the gray zone. In addition, exercise-induced RV contractile response was correlated with both patients' achieved exercise workload and their functional capacity, as it is reflected by the 6-MWT.

In particular, we found that post-exercise TR velocity $>3.4 \mathrm{~m} / \mathrm{s}$, which corresponds to a sPAP $\approx 50 \mathrm{mmHg}$, had a good diagnostic accuracy for the identification of PAH validated by RHC. Our study is the first to address this issue by adopting the recently proposed cutoff value of mean PAP $>20 \mathrm{mmHg}$ for the diagnosis of PAH measured by RHC. This new value has already been endorsed by the 2020 guidelines for the management of adult congenital heart disease [23].

There are few data assessing the sensitivity and specificity of EDE in identifying PAH confirmed by RHC in patients with SSc [12,24]. Steen et al. [12] reported that among 54 patients with SSc and clinical characteristics of high risk for PAH, $44 \%$ had a positive treadmill exercise test, defined as an increase in sPAP $\geq 20 \mathrm{mmHg}$ over the resting rate, and RHC confirmed PH in 81\% of them. Baptista et al. [13] in 2016 reviewed 15 studies which enrolled 1242 patients with SSc who performed EDE. The weighted mean sPAP on exercise was $43 \mathrm{mmHg}$, the mean increase in SPAP was $15 \mathrm{mmHg}$ and more than half of the studies reported mean exercise sPAP $\geq 40 \mathrm{mmHg}$. However, it was not possible for the authors to reach definite conclusions on the value of EDE due to the great heterogeneity in the methods, the characteristics of the recruited populations, the protocols and the definition of the positive results.

This great heterogeneity does not allow us to compare our results with previous studies. We recruited asymptomatic or oligosymptomatic patients with SSc whose echocardiographic findings were equivocal for $\mathrm{PH}$. In addition, we applied the recently proposed cutoff value of mean PAP $>20 \mathrm{mmHg}$ for the definition of $\mathrm{PH}$, which has not been applied in other studies.

Previous studies have reported a high prevalence of exercise-induced $\mathrm{PH}$ in SSc patients. Using cutoff values of sPAP $>40$ or $>50 \mathrm{mmHg}, 40-60 \%$ of patients with SSc develop exercise-induced $\mathrm{PH}$ [25-28]. However, the interpretation of sPAP elevations in the setting of SSc is complex since it is multifactorial, and its exact natural history is unknown [28]. There are several determinants of exercise-induced PH in SSc patients, such as reduced pulmonary vascular reserve due to early pulmonary arterial vasculature remodeling, LV diastolic dysfunction and lung interstitial fibrosis.

We selected patients without systolic or prominent diastolic LV dysfunction or abnormal pulmonary function tests. By minimizing the contribution of left heart disease (group 
$2 \mathrm{PH}$ ) or lung disease (group $3 \mathrm{PH}$ ) in the development of $\mathrm{PH}$, exercise-induced elevations in sPAP are likely to be caused mainly by abnormal pulmonary vascular response and represent mostly an early phase of PAH. In our study, the minor impact of diastolic function in the elevation of post-exercise SPAP is supported by the lack of increase of post-exercise $\mathrm{E} / \mathrm{e}^{\prime}>15$, a value that has been set as the threshold for pathologically elevated PAWP [29]. A number of studies have shown a good correlation between exercise E/e' with PAWP simultaneously measured with $\mathrm{RCH}$ in patients with preserved LV function [30,31].

Another critical component of exercise-induced $\mathrm{PH}$ is the magnitude of $\mathrm{CO}$ increase. In normal subjects, sPAP increases to $34.3 \pm 7.5 \mathrm{mmHg}$, in parallel to large elevations in $\mathrm{CO}(\approx 20 \mathrm{~L} / \mathrm{min})$ [32]. However, in SSc, sPAP is disproportionally elevated in relation to concomitant elevations of $\mathrm{CO}$ during exercise. It has been reported that for a significantly lower $\mathrm{CO}(<8-10 \mathrm{~L} / \mathrm{min})$ achieved in SSc studies, sPAP increased to approximately $47 \mathrm{mmHg}$ [13]. The relatively small CO increase during exercise in SSc may be explained by limited exercise capacity due to interstitial lung fibrosis, PVD, osteoarticular issues or deconditioning [13]. Therefore, interpretation of exercise-induced increases in sPAP should ideally be performed in relation to blood flow changes. $\triangle \mathrm{PAP} / \triangle \mathrm{CO}$ slopes reflecting pulmonary vascular reserve calculated by measurement of continuous pressure-flow values during exercise seem to be a more accurate determinant of exercise-induced $\mathrm{PH}$ in SSc [33]. Therefore, performance of exercise with parallel RHC may be meaningful in SSc patients with normal resting sPAP for prognostic stratification since it has been shown that steeper increases in mean PAP/CO slope are predictive of future development of $\mathrm{PH}$ [34]. However, this approach is invasive and cannot easily be applied in daily clinical practice as a screening test.

Our hypothesis is that in early stages of PVD in SSc patients, resting sPAP may be normal or slightly elevated due to pulmonary vasculature reserve. However, pulmonary flow augmentation during exercise in the context of inadequate adaptation of pulmonary vasculature due to impaired vascular distensibility may lead to a hemodynamic derangement, with a subsequent disproportionate increase in mean PAP [35].

We found that SSc patients with PAH had less RV inotropic reserve with exercise compared to those without $\mathrm{PAH}$, and that exercise-induced contractile response was correlated with both patients' achieved exercise workload and functional capacity. Interestingly, this association was found when RV inotropic response was assessed with $\Delta(\mathrm{S}(\mathrm{RV}))$ but not with $\Delta$ (TAPSE). Although both measures represent longitudinal contraction of RV at the level of tricuspid annulus, it has been suggested that $S$ wave may be more sensitive than TAPSE to assess RV inotropic response [36]. We also found a positive correlation of post-exercise TR velocity with resting mean PAP and sPAP obtained by RHC, while maximum workload was inversely correlated with mean PAP. The latter has been reported previously [11] and it is reasonable to speculate that the higher mean resting PAP is associated with higher PVR during exercise, with subsequent reduced carbon dioxide exchange, increased anaerobic metabolism, muscle fatigue and reduction in exercise capacity.

Of note, there was no difference in the 6-MWT between SSc patients with PAH and those without PAH. This may be explained by a "ceiling effect" of the 6-MWT which may mask the disability of less-symptomatic PAH patients. Therefore, the 6-MWT was relatively preserved in our $\mathrm{PAH}$ patients who were asymptomatic or mildly symptomatic, probably due its low sensitivity to reveal functional impairment in this subgroup of $\mathrm{PAH}$ patients [37].

It should be mentioned that EDE may not be applicable in all asymptomatic or oligosymptomatic SSc patients, since (a) a small proportion of patients ( $6 \%$ in our study) may not be able to perform a treadmill exercise test due to severe myalgias, arthralgias and musculoskeletal problems being part of their disease process, and (b) not all patients undergoing EDE have a reliably measurable TR velocity immediately post-exercise. In our study, $6 \%$ of our patients had a poor-quality Doppler signal, and thus were excluded from further analysis. 


\section{Study Limitations}

The main limitation of this study is the relatively small sample size.

\section{Conclusions}

EDE has a good diagnostic accuracy for the identification of PAH in selected asymptomatic or oligosymptomatic patients with SSc, whose baseline echocardiographic measurements for PH lie in the gray zone. Thus, it might be useful to perform EDE in SSc with equivocal clinical and echocardiographic findings of $\mathrm{PH}$, and if abnormal, to proceed to RHC. Furthermore, EDE provides information regarding the inotropic reserve of RV, but its clinical usefulness and prognostic value need to be investigated in prospective studies.

Author Contributions: Conceptualization, L.S.R.; A.A. and S.E.O.; writing the manuscript, L.S.R.; data curation, L.S.R.; K.P.; G.M.; A.A.; I.T. and D.K.; methodology, L.S.R.; A.A. and I.T.; formal analysis, C.V.; review and editing of manuscript, A.A.; P.V., S.E.O. and E.K.I. All authors have read and agreed to the published version of the manuscript.

Funding: This research received no external funding.

Institutional Review Board Statement: The study was approved by the Ethics Committee of University General Hospital Attikon. Approval number: EB $\Delta 36$. Date of approval 14 February 2014.

Informed Consent Statement: All subjects provided signed informed consent form.

Data Availability Statement: The data presented in this study are available on reasonable request from the corresponding author (L.S.R.). The data are not publicly available due to privacy and ethical issues.

Conflicts of Interest: The authors declare no conflict of interest.

\section{References}

1. Barnes, J.; Mayes, M.D. Epidemiology of systemic sclerosis: Incidence, prevalence, survival, risk factors, malignancy, and environmental triggers. Curr. Opin. Rheumatol. 2012, 24, 165-170. [CrossRef]

2. Mathai, S.C.; Hassoun, P.M. Pulmonary arterial hypertension associated with systemic sclerosis. Expert Rev. Respir. Med. 2011, 5, 267-279. [CrossRef] [PubMed]

3. Galiè, N.; Humbert, M.; Vachiéry, J.-L.; Gibbs, S.; Lang, I.M.; Kaminski, K.A.; Simonneau, G.; Peacock, A.; Noordegraaf, A.V.; Beghetti, M.; et al. 2015 ESC/ERS Guidelines for the diagnosis and treatment of pulmonary hypertension. Eur. Heart J. 2016, 37, 67-119. [CrossRef] [PubMed]

4. MacGregor, A.; Canavan, R.; Knight, C.; Denton, C.P.; Davar, J.; Coghlan, J.; Black, C.M. Pulmonary hypertension in systemic sclerosis: Risk factors for progression and consequences for survival. Rheumatology 2001, 40, 453-459. [CrossRef] [PubMed]

5. Kolstad, K.D.; Li, S.; Steen, V.; Chung, L.; PHAROS Investigators. Long-term outcomes in systemic sclerosis-associated pulmonary arterial hypertension from the pulmonary hypertension assessment and recognition of outcomes in scleroderma registry (PHAROS). Chest 2018, 154, 862-871. [CrossRef]

6. Hoeper, M.M.; Apitz, C.; Grünig, E.; Halank, M.; Ewert, R.; Kaemmerer, H.; Kabitz, H.-J.; Kähler, C.; Klose, H.; Leuchte, H.; et al. Targeted therapy of pulmonary arterial hypertension: Updated recommendations from the Cologne Consensus Conference 2018. Int. J. Cardiol. 2018, 272, 37-45. [CrossRef]

7. Hachulla, E.; Launay, D.; Boucly, A.; Mouthon, L.; de Groote, P.; Cottin, V.; Pugnet, G.; Prévôt, G.; Bourlier, D.; Dauphin, C.; et al. Survival improved in patients aged $\leq 70$ years with systemic sclerosis-associated pulmonary arterial hypertension during the period 2006 to 2017 in France. Chest 2020, 157, 945-954. [CrossRef]

8. Galiè, N.; Rubin, L.; Hoeper, M.; Jansa, P.; Al-Hiti, H.; Meyer, G.; Chiossi, E.; Kusic-Pajic, A.; Simonneau, G. Treatment of patients with mildly symptomatic pulmonary arterial hypertension with bosentan (EARLY study): A double-blind, randomised controlled trial. Lancet 2008, 371, 2093-2100. [CrossRef]

9. Denton, C.P.; Cailes, J.B.; Phillips, G.D.; Wells, A.U.; Black, C.M.; Bois, R.M. Comparison of Doppler echocardiography and right heart catheterization to assess pulmonary hypertension in systemic sclerosis. Br. J. Rheumatol. 1997, 36, 239-243. [CrossRef]

10. Coghlan, J.G.; Denton, C.P.; Grünig, E.; Bonderman, D.; Distler, O.; Khanna, D.; Müller-Ladner, U.; Pope, J.; Vonk, M.C.; Doelberg, M.; et al. Evidence-based detection of pulmonary arterial hypertension in systemic sclerosis: The DETECT study. Ann. Rheum. Dis. 2014, 73, 1340-1349. [CrossRef]

11. Alkotob, M.L.; Soltani, P.; Sheatt, M.A.; Katsetos, M.C.; Rothfield, N.; Hager, W.D.; Foley, R.J.; Silverman, D.I. Reduced exercise capacity and stress- induced pulmonary hypertension in patients with scleroderma. Chest 2006, 130, 176-181. [CrossRef]

12. Steen, V.; Chou, M.; Shanmugam, V.; Mathias, M.; Kuru, T.; Morrissey, R. Exercise-induced pulmonary arterial hypertension in patients with systemic sclerosis. Chest 2008, 134, 146-151. [CrossRef] 
13. Baptista, R.; Serra, S.; Martins, R.; Teixeira, R.; Castro, G.; Salvador, M.J.; Da Silva, J.A.P.; Santos, L.; Monteiro, P.; Pêgo, M. Exercise echocardiography for the assessment of pulmonary hypertension in systemic sclerosis: A systematic review. Arthritis Res. Ther. 2016, 18, 153. [CrossRef] [PubMed]

14. Chia, E.M.; Lau, E.M.; Xuan, W.; Celermajer, D.S.; Thomas, L. Exercise testing can unmask right ventricular dysfunction in systemic sclerosis patients with normal resting pulmonary artery pressure. Int. J. Cardiol. 2016, 204, 179-186. [CrossRef] [PubMed]

15. Simonneau, G.; Montani, D.; Celermajer, D.; Denton, C.P.; Gatzoulis, M.A.; Krowka, M.; Williams, P.G.; Souza, R. Haemodynamic definitions and updated clinical classification of pulmonary hypertension. Eur. Respir J. 2019, 53, 1801913. [CrossRef] [PubMed]

16. Coghlan, J.G.; Galiè, N.; Barberà, J.A.; Frost, A.E.; Ghofrani, A.; Hoeper, M.; Kuwana, M.; McLaughlin, V.V.; Peacock, A.J.; Simonneau, G.; et al. AMBITION investigators. Initial combination therapy with ambrisentan and tadalafil in connective tissue disease-associated pulmonary arterial hypertension (CTD-PAH): Subgroup analysis from the AMBITION trial. Ann. Rheum. Dis. 2017, 76, 1219-1227. [CrossRef]

17. Lang, R.M.; Badano, L.P.; Mor-Avi, V.; Afilalo, J.; Armstrong, A.; Ernande, L.; Flachskampf, F.A.; Foster, E.; Goldstein, S.A.; Kuznetsova, T.; et al. Recommendations for cardiac chamber quantification by echocardiography in adults: An update from the American Society of Echocardiography and the European Association of Cardiovascular Imaging. J. Am. Soc. Echocardiogr. 2015, 28, 1-39. [CrossRef]

18. Nagueh, S.F.; Smiseth, O.A.; Appleton, C.P.; Byrd, B.F.; Dokainish, H.; Edvardsen, T.; Flachskampf, F.A.; Gillebert, T.; Klein, A.L.; Lancellotti, P.; et al. Recommendations for the evaluation of left ventricular diastolic function by echocardiography: An update from the American Society of Echocardiography and the European Association of Cardiovascular Imaging. J. Am. Soc. Echocardiogr. 2016, 29, 277-314. [CrossRef]

19. Rudski, L.G.; Lai, W.W.; Afilalo, J.; Hua, L.; Handschumacher, M.; Chandrasekaran, K.; Solomon, S.D.; Louie, E.K.; Schiller, N.B. Guidelines for the echocardiographic assessment of the right heart in adults: A report from the American Society of Echocardiography endorsed by the European Association of Echocardiography, a registered branch of the European Society of Cardiology, and the Canadian Society of Echocardiography. J. Am. Soc. Echocardiogr. 2010, 23, 685-713. [CrossRef]

20. Rallidis, L.; Cokkinos, P.; Tousoulis, D.; Nihoyannopoulos, P. Comparison of dobutamine and treadmill exercise echocardiography in inducing ischemia in patients with coronary artery disease. J. Am. Coll. Cardiol. 1997, 30, 1660-1668. [CrossRef]

21. Altman, D.G.; Machin, D.; Bryant, T.N.; Gardner, M.J. (Eds.) Statistics with Confidence, 2nd ed.; BMJ Books: London, UK, 2000.

22. Mercaldo, N.D.; Lau, K.F.; Zhou, X.H. Confidence intervals for predictive values with an emphasis to case-control studies. Stat. Med. 2007, 26, 2170-2183. [CrossRef]

23. Baumgartner, H.; De Backer, J.; Babu-Narayan, S.V.; Budts, W.; Chessa, M.; Diller, G.-P.; Lung, B.; Kluin, J.; Lang, I.M.; Meijboom, F.; et al. 2020 ESC Guidelines for the management of adult congenital heart disease. Eur. Heart J. 2021, 42, 563-645. [CrossRef]

24. Nagel, C.; Henn, P.; Ehlken, N.; D’Andrea, A.; Blank, N.; Bossone, E.; Böttger, A.; Fiehn, C.; Fischer, C.; Lorenz, H.-M.; et al. Stress Doppler echocardiography for early detection of systemic sclerosis-associated pulmonary arterial hypertension. Arthritis Res Ther. 2015, 17, 165. [CrossRef]

25. Reichenberger, F.; Voswinckel, R.; Schulz, R.; Mensch, O.; Ghofrani, H.; Olschewski, H.; Seeger, W. Noninvasive detection of early pulmonary vascular dysfunction in scleroderma. Respir. Med. 2009, 103, 1713-1718. [CrossRef]

26. Voilliot, D.; Magne, J.; Dulgheru, R.; Kou, S.; Henri, C.; Laaraibi, S.; Sprynger, M.; Andre, B.; Piérard, L.A.; Lancellotti, P. Determinants of exercise-induced pulmonary arterial hypertension in systemic sclerosis. Int. J. Cardiol. 2014, 173, 373-379. [CrossRef]

27. Pignone, A.; Mori, F.; Pieri, F.; Oddo, A.; Galeota, G.; Fiori, G.; Del Rosso, A.; Perfetto, F.; Becucci, A.; Livi, R.; et al. Exercise Doppler echocardiography identifies preclinic asymptomatic pulmonary hypertension in systemic sclerosis. Ann. N. Y. Acad. Sci. 2007, 1108, 291-304. [CrossRef] [PubMed]

28. Lau, E.M.T.; Manes, A.; Celermajer, D.S.; Galiè, N. Early detection of pulmonary vascular disease in pulmonary arterial hypertension: Time to move forward. Eur. Heart J. 2011, 32, 2489-2498. [CrossRef]

29. Prasad, S.B.; Holland, D.J.; Atherton, J.J. Diastolic stress echocardiography: From basic principles to clinical applications. Heart 2018, 104, 1739-1748. [CrossRef]

30. Burgess, M.I.; Jenkins, C.; Sharman, J.E.; Marwick, T.H. Diastolic stress echocardiography: Hemodynamic validation and clinical significance of estimation of ventricular filling pressure with exercise. J. Am. Coll. Cardiol. 2006, 47, 1891-1900. [CrossRef] [PubMed]

31. Obokata, M.; Kane, G.C.; Reddy, Y.N.; Olson, T.P.; Melenovsky, V.; Borlaug, B.A. Role of diastolic stress testing in the evaluation for heart failure with preserved ejection fraction: A simultaneous invasive-echocardiographic study. Circulation 2017, 135, 825-838. [CrossRef] [PubMed]

32. Kovacs, G.; Berghold, A.; Scheidl, S.; Olschewski, H. Pulmonary arterial pressure during rest and exercise in healthy subjects: A systematic review. Eur. Respir. J. 2009, 34, 888-894. [CrossRef] [PubMed]

33. Lewis, G.D.; Bossone, E.; Naeije, R.; Grünig, E.; Saggar, R.; Lancellotti, P.; Ghio, S.; Varga, J.; Rajagopalan, S.; Oudiz, R.J.; et al. Pulmonary vascular hemodynamic response to exercise in cardiopulmonary diseases. Circulation 2013, 128, 1470-1479. [CrossRef]

34. Kusunose, K.; Yamada, H.; Hotchi, J.; Bando, M.; Nishio, S.; Hirata, Y.; Ise, T.; Yamaguchi, K.; Yagi, S.; Soeki, T.; et al. Prediction of future overt pulmonary hypertension by 6-min walk stress echocardiography in patients with connective tissue disease. J. Am. Coll. Cardiol. 2015, 66, 376-384. [CrossRef] 
35. Tolle, J.J.; Waxman, A.B.; Van Horn, T.L.; Pappagianopoulos, P.P.; Systrom, D.M. Exercise-induced pulmonary arterial hypertension. Circulation 2008, 118, 2183-2189. [CrossRef]

36. Sharma, T.; Lau, E.M.; Choudhary, P.; Torzillo, P.J.; Munoz, P.A.; Simmons, L.R.; Naeije, R.; Celermajer, D.S.; Torres, M.; GarcíaGarcía, L.; et al. Dobutamine stress for evaluation of right ventricular reserve in pulmonary arterial hypertension. Eur. Respir. J. 2015, 45, 700-708. [CrossRef] [PubMed]

37. Gaine, S.; Simonneau, G. The need to move from 6-minute walk distance to outcome trials in pulmonary arterial hypertension. Eur. Respir. Rev. 2013, 22, 487-494. [CrossRef] [PubMed] 